\title{
Flood Frequency Analysis Using Gumbel's Distribution Method: A Case Study of Lower Mahi Basin, India
}

\author{
Nirman Bhagat \\ Department of Civil Engineering, Indus University, Ahmedabad, India
}

Email address:

nirmanbhagat@gmail.com

To cite this article:

Nirman Bhagat. Flood Frequency Analysis Using Gumbel's Distribution Method: A Case Study of Lower Mahi Basin, India. Journal of Water Resources and Ocean Science. Vol. 6, No. 4, 2017, pp. 51-54. doi: 10.11648/j.wros.20170604.11

Received: April 29, 2017; Accepted: May 10, 2017; Published: July 4, 2017

\begin{abstract}
Estimation of Peak Flood Discharge for a desired return period is a pre-requisite for planning, design and management of hydraulic structures like barrages, dams, spillways, bridges etc. This paper presents results of a study carried out at analyzing the frequency of Lower Mahi River floods using the Gumbel's distribution method which is one of the probability distribution methods used to model stream flows. The method was used to model the annual maximum discharge of the river from Wanakbori Weir (regulating structure in the river) for a period of 30 years (1980 to 2009). From the regression analysis equation, $\mathrm{R}^{2}$ gives a value of 0.964 which shows that Gumbel's distribution is suitable for predicting the expected flow in the river. Using the same method the peak flood values for different Return Periods were also obtained, which can prove useful for the storm management in the area.
\end{abstract}

Keywords: Flood Frequency Analysis, Gumbel's Distribution Method, Lower Mahi River

\section{Introduction}

In the planning and design of water resources projects, engineers and planners are often interested to determine the magnitude and frequency of floods that will occur at the project areas. Besides the rational method, unit hydrograph method and rainfall-runoff models method, frequency analysis is one of the main techniques used to define the relationship between the magnitude of an event and the frequency with which that event is exceeded.

Flood Frequency Analysis is the estimation of how often a specified event will occur. Before the estimation is carried out, analysis of the stream flow data plays a very important role in order to obtain a probability distribution of floods [11]. Flood frequency analysis (FFA) is most commonly used by engineers and hydrologists worldwide and basically consists of estimating flood peak quantities for a set of nonexceedance probabilities.

Flood frequency analysis involves the fitting of a probability model to the sample of annual flood peaks recorded over a period of observation, for a catchment of a given region. The model parameters established can then be used to predict the extreme events of large recurrence interval. Reliable flood frequency estimates are vital for floodplain management; to protect the public, minimize flood related costs to government and private enterprises, for designing and locating hydraulic structures and assessing hazards related to the development of flood plains [10].

Although studies have employed several statistical distributions to quantify the likelihood and intensity of floods, none had gained worldwide acceptance and is specific to any country [3]. In order to ensure safety and economic hydrologic design in the catchment area, the Gumbel distribution, a stochastic generating structure that produce random outcomes was used to model the annual peak discharge data of Lower Mahi river from 1989 to 2009.

The main objective of the study was to carry out the Flood Frequency Analysis for the Lower Mahi River using the discharge data of Wanakbori weir, which is the only regulating structure in the Lower Mahi River. The results of the analysis generated from the study gives detailed information of likely flow discharge to be expected in the river at the various return periods based on the observed data. This information will be very useful for engineering purposes such as when designing structures in or near the river that may be affected by the flood as well as in designing the flood structure to protect against the 
expected events. [4]. This may include the design of dam, bridges and flood control structures which will reduce flood disaster in the catchment or assist considerably in storm water management in the region.

\section{Study Area \& Data Collection}

Mahi River is one of the major west flowing interstate river of India, draining into the Gulf of Khambhat. The Mahi basin is comprised of two sub-basins:- Mahi upper sub basin of $(65.11 \%$ of total basin area) consisting of 41 watersheds and Mahi lower sub basin $(34.89 \%$ of total basin area) consisting of 22 watersheds. It lies between $72^{0} 15^{\text {ee }} 00^{\prime \prime} \mathrm{E}$ to $78^{0} 15^{\circ e} 00^{\prime \prime} \mathrm{E}$ and $22^{\circ} \mathrm{N}$ to $22^{0} 40^{\circ e} 00^{\prime \prime} \mathrm{N}$ respectively. The basin map is shown in Fig. 1. Only the lower Mahi Basin is considered for the present study.

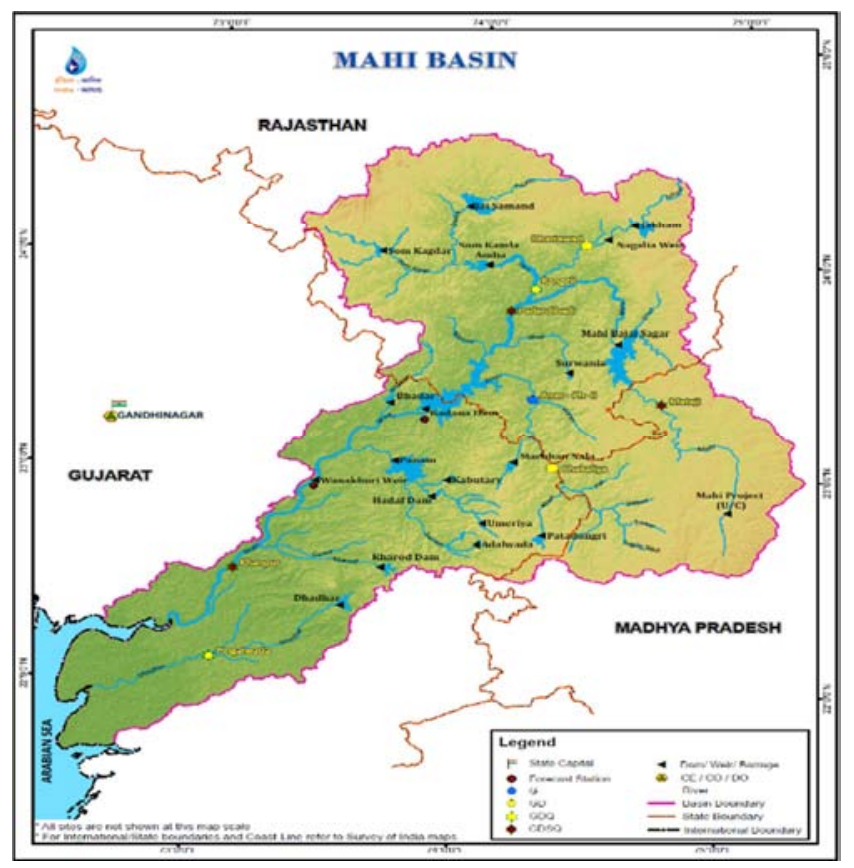

Figure 1. Mahi Basin.

In the lower Mahi River, the flow is regulated by Wanakbori Weir. It is the only major water retaining and regulating structure in the river. The flow in the river is due to the releases made from the Weir and hence the release data of the same was considered for the study. The Maximum Discharge $\left(\mathrm{m}^{3} / \mathrm{s}\right)$ from the weir was considered from the period of 1980 to 2009 for the analysis.

\section{Gumbel's Method}

Gumbel's distribution is a statistical method often used for predicting extreme hydrological events such as floods [12] [1] [9]. In this study it has been applied for flood frequency analysis because (a) the river is less regulated, hence is not significantly affected by reservoir operations, diversions or urbanization; (b) flow data are homogeneous and independent hence lack long-term trends; and (c) peak flow data cover a relatively long record (more than 10 years) and is of good quality (d) there is no major tributary of the river whose inflow can affect the flood peak.

The equation for Gumbel's distribution as well as to the procedure with a return period $\mathrm{T}$ is given as,

$$
\mathrm{X}_{\mathrm{T}}=\bar{X}+\mathrm{K} \cdot \sigma_{\mathrm{x}}
$$

Where,

$\sigma_{\mathrm{x}}=$ Standard deviation of the Sample Size

$\mathrm{K}=$ Frequency Factor, which is expressed as, $\mathrm{K}=\frac{Y t-\overline{\overline{Y n}}}{S n}$

In which, $\mathrm{Y}_{\mathrm{T}}=$ Reduced Variate, $\mathrm{Y}_{\mathrm{T}}=-\left[\operatorname{Ln} . \operatorname{Ln} .\left(\frac{T}{T-1}\right)\right]$

The values of $\overline{Y n}$ and $\mathrm{S}_{\mathrm{n}}$ are selected from Gumbel's Extreme Value Distribution considered depending on the sample size.

\section{Methodology}

The maximum discharge data of Wanakbori Weir, from 1980-2009 (30 years flood data) were considered for the flood frequency analysis applying the Gumbel's distribution. The steps to estimate the design flood for any return period, given by [2] is as follows:

Step I: Annual peak flood data was assembled from 1980 to 2009.

Step II: From the maximum flood data for $\mathrm{n}$ years, the mean $\bar{X}$ and standard deviation $\sigma_{\mathrm{x}}$ are computed using:

$$
\sum_{i=1}^{n} X i \text { And } \sigma_{\mathrm{x}}=\sqrt{\frac{1}{(n-1)} \sum_{i=1}^{n}(x-\bar{x})^{2}}
$$

StepIII: From the Gumbel's Extreme Value distribution table, the value $\overline{Y n}$ and $S_{n}$ are taken as 0.5362 and 1.1124 .

Step VI: From the given return period $\mathrm{T}_{\mathrm{r}}$, the reduced variate $Y_{T}$ is computed using Equation (3).

Step V: From $\overline{Y n}, \mathrm{~S}_{\mathrm{n}}$ and $\mathrm{Y}_{\mathrm{T}}$, the flood frequency factor $\mathrm{K}$ is computed using Equation (2).

Step VI: With use of Equation (1), the magnitude of flood is computed.

It is of great importance to confirm if the observed flood data collected in the catchment follows Gumbel's distribution or not. In order to achieve this, the observed data is arranged in descending order (the highest coming first) and assigning the return period for each flood; the reduced variate corresponding to each flood is computed using Equation (3). A plot of the reduced variate and magnitude of flood is made on ordinary graph paper. If an eye fits to this plot suggest a straight line, then it is reasonable to conclude that the Gumbel's distribution is a good fit for the observed flood data.

\section{Results}

The Gumbel's distribution analysis was done following the above methodology and the results obtained are shown in Table 1. Also a plot of reduced variate $\mathrm{v} / \mathrm{s}$ flood peak was plotted for lower Mahi River, which is shown in Figure 2. 
Table 1. Computation Table.

\begin{tabular}{|c|c|c|c|c|c|c|}
\hline Year & Peak Flood $\left(\mathrm{m}^{3} / \mathrm{s}\right)$ & $\begin{array}{l}\text { Peak Flood in } \\
\text { descending order }\left(\mathrm{m}^{3} / \mathrm{s}\right)\end{array}$ & Order (m) & $S_{x}{ }^{2}=\left(n-{ }^{-} x\right)^{2}$ & $\begin{array}{l}\text { Return Period } \\
\mathrm{T}_{\mathrm{r}}=\frac{n+1}{m}\end{array}$ & $\begin{array}{l}\text { Reduced Variate } \\
\mathrm{Y}=-\ln \cdot \ln \frac{T r}{T r-1}\end{array}$ \\
\hline 1980 & 6591.25 & 32556.50 & 1 & 497934678.8 & 31 & 3.417637 \\
\hline 1981 & 21505.55 & 29287.71 & 2 & 362737323.3 & 15.5 & 2.70768 \\
\hline 1982 & 3055.07 & 21505.55 & 3 & 126866431.1 & 10.33333 & 2.284915 \\
\hline 1983 & 4065.88 & 21255.37 & 4 & 121293316.1 & 7.75 & 1.979413 \\
\hline 1984 & 16496.24 & 16662.56 & 5 & 41222926.19 & 6.2 & 1.737893 \\
\hline 1985 & 9515.02 & 16496.24 & 6 & 39114855.03 & 5.166667 & 1.536599 \\
\hline 1986 & 10909.97 & 15391.78 & 7 & 26519708.46 & 4.428571 & 1.362838 \\
\hline 1987 & 14265.89 & 14722.93 & 8 & 20078257.88 & 3.875 & 1.209009 \\
\hline 1988 & 11590.96 & 14709.88 & 9 & 19961469.17 & 3.444444 & 1.070186 \\
\hline 1989 & 1140.04 & 14353.17 & 10 & 16901307.65 & 3.1 & 0.942982 \\
\hline 1990 & 29287.71 & 14265.89 & 11 & 16191290.52 & 2.818182 & 0.824955 \\
\hline 1991 & 15391.78 & 12584.53 & 12 & 5487217.516 & 2.583333 & 0.714272 \\
\hline 1992 & 16662.56 & 11590.96 & 13 & 1819567.091 & 2.384615 & 0.609513 \\
\hline 1993 & 14722.93 & 10909.97 & 14 & 446112.117 & 2.214286 & 0.509537 \\
\hline 1994 & 21255.37 & 10141.09 & 15 & 10191.9201 & 2.066667 & 0.413399 \\
\hline 1995 & 1060.49 & 10010.42 & 16 & 53654.30996 & 1.9375 & 0.320292 \\
\hline 1996 & 10010.42 & 9601.96 & 17 & 409716.0786 & 1.823529 & 0.229501 \\
\hline 1997 & 14353.17 & 9515.02 & 18 & 528573.6242 & 1.722222 & 0.140369 \\
\hline 1998 & 9601.96 & 6591.25 & 19 & 13328359.33 & 1.631579 & 0.052262 \\
\hline 1999 & 10141.09 & 4065.88 & 20 & 38145048.69 & 1.55 & -0.03546 \\
\hline 2000 & 175.00 & 3055.07 & 21 & 51652629.06 & 1.47619 & -0.12346 \\
\hline 2001 & 200.00 & 2240.59 & 22 & 64023282.92 & 1.409091 & -0.2125 \\
\hline 2002 & 225.00 & 2140.41 & 23 & 65636637.77 & 1.347826 & -0.30347 \\
\hline 2003 & 2240.59 & 1140.04 & 24 & 82846518.69 & 1.291667 & -0.39748 \\
\hline 2004 & 12584.53 & 1060.49 & 25 & 84300996.29 & 1.24 & -0.49605 \\
\hline 2005 & 2140.41 & 616.22 & 26 & 92656530.61 & 1.192308 & -0.60133 \\
\hline 2006 & 32556.50 & 225.00 & 27 & 100341290.7 & 1.148148 & -0.71671 \\
\hline 2007 & 14709.88 & 200.00 & 28 & 100842768.2 & 1.107143 & -0.84817 \\
\hline 2008 & 190.00 & 190.00 & 29 & 101043709.2 & 1.068966 & -1.00826 \\
\hline 2009 & 616.22 & 175.00 & 30 & 101345495.7 & 1.033333 & -1.23372 \\
\hline SUM & & 307261.49 & & 2193739864 & & \\
\hline AVERAGE & & 10242.05 & & & & \\
\hline S.D. & & & & 106868547.5 & & \\
\hline
\end{tabular}

S.D. - Standard Deviation

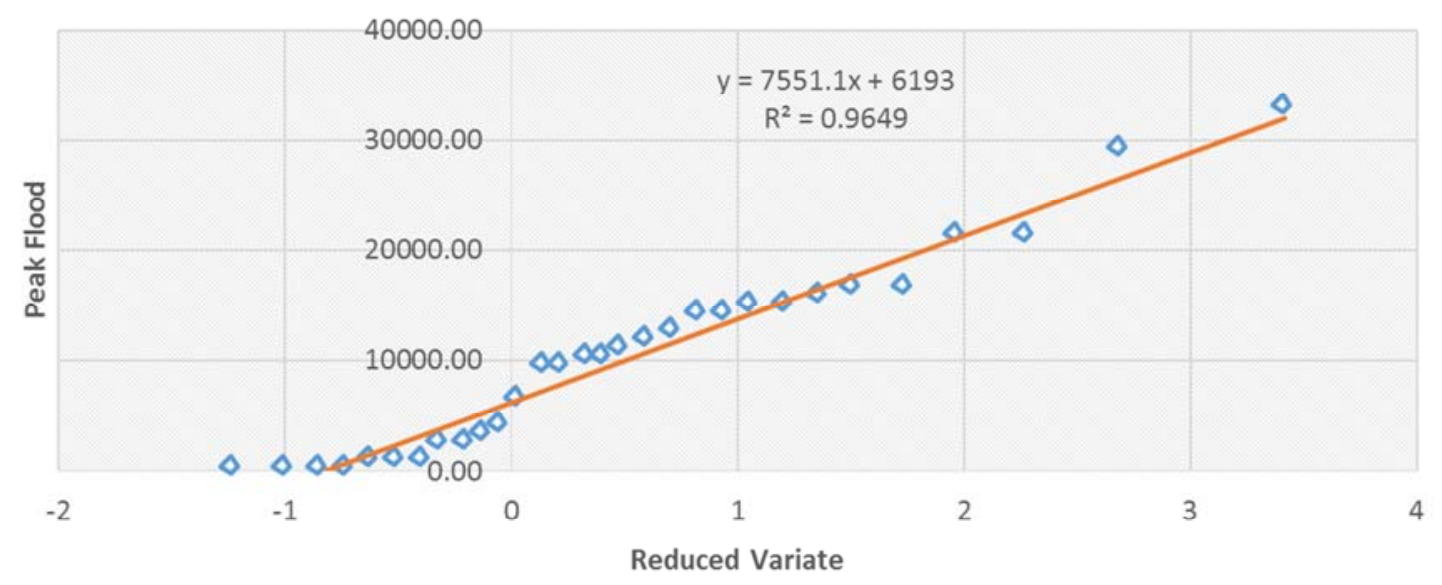

Figure 2. Plot of Reduced Variate v/s Peak Flood for Mahi River.

The above results show that the maximum flow of $32556 \mathrm{~m}^{3} / \mathrm{s}$ was recorded in 2006 while the lowest flood flow of $175 \mathrm{~m}^{3} / \mathrm{s}$ was recorded in 2000. The 30-year mean instantaneous flood flow is $10242 \mathrm{~m}^{3} / \mathrm{s}$ with a coefficient of variability, $C V$ of $85 \%$. Using the Gumbel's distribution analysis, the floods with different recurrence intervals were also computed and the same are shown in Table 2. 
Table 2. Computation of Expected Flood along Mahi River.

\begin{tabular}{|c|c|c|c|}
\hline Return Period $(T)$ in years & Reduced Variate $Y=-\ln . \ln \frac{T r}{T r-1}$ & Frequency Factor, $K_{(T)}=Y_{T}-\overline{Y n} \sigma_{n}$ & Expected Flood, $\mathbf{X}_{\mathrm{T}}=\bar{x}+\mathbf{K}_{\mathrm{T}}$. $\mathbf{S}_{\mathbf{x}}$ \\
\hline 2 & 0.366513 & -0.1525414 & 8937.668 \\
\hline 10 & 2.250367 & 1.54096308 & 23418.83 \\
\hline 50 & 3.901939 & 3.02565503 & 36114.43 \\
\hline 100 & 4.600149 & 3.65331646 & 41481.56 \\
\hline 150 & 5.007293 & 4.01932099 & 44611.26 \\
\hline 200 & 5.295812 & 4.27868765 & 46829.11 \\
\hline 300 & 5.702113 & 4.64393517 & 49952.34 \\
\hline 400 & 5.990213 & 4.90292453 & 52166.96 \\
\hline
\end{tabular}

The results show the expected floods in the river reach for return periods of $2 \mathrm{yrs}, 5 \mathrm{yrs}, 10 \mathrm{yrs}, 25 \mathrm{yrs}, 50 \mathrm{yrs}, 100 \mathrm{yrs}$, $200 y r s$ and $400 y r s$. From here, other values not shown in chart can be extrapolated or can be computed using the above mentioned method.

\section{Conclusion}

From the flood frequency analysis carried out for Lower Mahi River using 30 year's annual peak flow data. Figure 2 shows a plot of the reduced variate and peak flood of the river using the observed data. From the trend line equation, $\mathrm{R}^{2}$ gives a value of 0.9649 . The value $\mathrm{r}=0.9649$ shows that the pattern of the scatter is narrow and that Gumbel's distribution method is suitable for predicting expected flow in the river. Also the mean instantaneous flow in the river is $10242 \mathrm{~m}^{3} / \mathrm{s}$ which is having a return period of about 2 years as shown in Table 2 and it is visible in the flood peak data also. This means the prediction of floods in the basin is nearly accurate. This prediction of flood can be utilized in the designing of important hydraulic structures and bridges in the river reach. Also in case of extreme floods emergency evacuation of people can be carried out well in advance. Similar study can also be carried out on some other study region, as the method used for the study is having a constant formula, which remains spatially constant.

\section{References}

[1] C. T. Haan, "Statistical Methods in Hydrology." Iowa State University Press, Ames, Iowa. I '. Haefner, Journal of Water, 1997.

[2] Chow, V. T., Maidment,. R., Mays, L. W. (1988), “Applied
Hydrology”. McGraw Hill Book Company, Singapore.

[3] G. S. Law, and G. D Tasker, "Flood-Frequency prediction methods for unregulated streams of Tennessee." Water Resources Investigations Report 03-4176, Nashville, Tennessee, 2003.

[4] Izinyon, O. C. and Igbinoba E. (2011), "Flood Frequency Analysis of Ikpoba River Catchment at Benin City gsing Log Pearson Type III distribution", (JETEAS) 2 (1): 50-55.

[5] J. R. Stedinger and R. M. Vogel, "Frequency analysis of extreme events." Handbook of Hydrology, chapter 18, McGraw-Hill, New York, 1993. Vol. 3, No. 10, 2013.

[6] Mujere, N. 2006. Impact of river flow changes on irrigation agriculture: A case study of Nyanyadzi irrigation scheme in Chimanimani district. MPhil Thesis, University of Zimbabwe, Harare.

[7] N. Mujere, "Flood frequency analysis using the Gumbel distribution." International Journal on Computer Science and Engineering (IJCSE), vol. 3, pp. 2774-2778, July 2011.

[8] O. Solomon and O. Prince. "Flood Frequency Analysis of Osse River Using Gumbel's Distribution". Civil and Environmental Research, pp. 55-60.

[9] Shaw, E. M. 1983. Hydrology in Practice. Van Nostrand Reinhold, UK.

[10] Tumbare, M. J. 2000. Mitigating floods in Southern Africa. Paper presented at the $1^{\text {st }}$ WARSFA/WaterNet Symposium: Sustainable Use of Water Resources, 1-2 November, Maputo.

[11] U. N. Ahmad, A. Shabri, and Z. A. Zakaria, "Flood frequency analysis of annual maximum stream flows using L-Moments and TL-Moments." Applied Mathematical Sciences, vol. 5, pp. 243-253, 2011.

[12] Zelenhasic, E. 1970. Theoretical Probability Distributions for Flood Peaks. Colorado University Press, Colorado. 